\title{
Removal of Pharmaceutical Residues by Ferrate(VI)
}

\author{
JiaQian Jiang*, Zhengwei Zhou
}

School of Engineering and Built Environment, Glasgow Caledonian University, Glasgow, Scotland, United Kingdom

\begin{abstract}
Background: Pharmaceuticals and their metabolites are inevitably emitted into the waters. The adverse environmental and human health effects of pharmaceutical residues in water could take place under a very low concentration range; from several $\mu \mathrm{g} / \mathrm{L}$ to $\mathrm{ng} / \mathrm{L}$. These are challenges to the global water industries as there is no unit process specifically designed to remove these pollutants. An efficient technology is thus sought to treat these pollutants in water and waste water.

Methodology/Major Results: A novel chemical, ferrate, was assessed using a standard jar test procedure for the removal of pharmaceuticals. The analytical protocols of pharmaceuticals were standard solid phase extraction together with various instrumentation methods including LC-MS, HPLC-UV and UV/Vis spectroscopy. Ferrate can remove more than $80 \%$ of ciprofloxacin (CIP) at ferrate dose of $1 \mathrm{mg} \mathrm{Fe} / \mathrm{L}$ and 30\% of ibuprofen (IBU) at ferrate dose of $2 \mathrm{mg} \mathrm{Fe} / \mathrm{L}$. Removal of pharmaceuticals by ferrate was $\mathrm{pH}$ dependant and this was in coordinate to the chemical/physical properties of pharmaceuticals. Ferrate has shown higher capability in the degradation of CIP than IBU; this is because CIP has electronrich organic moieties (EOM) which can be readily degraded by ferrate oxidation and IBU has electron-withdrawing groups which has slow reaction rate with ferrate. Promising performance of ferrate in the treatment of real waste water effluent at both $\mathrm{pH} 6$ and 8 and dose range of 1-5 mg Fe/L was observed. Removal efficiency of ciprofloxacin was the highest among the target compounds (63\%), followed by naproxen (43\%). On the other hand, n-acetyl sulphamethoxazole was the hardest to be removed by ferrate ( $8 \%$ only).
\end{abstract}

Conclusions: Ferrate is a promising chemical to be used to treat pharmaceuticals in waste water. Adjusting operating conditions in terms of the properties of target pharmaceuticals can maximise the pharmaceutical removal efficiency.

Citation: Jiang J, Zhou Z (2013) Removal of Pharmaceutical Residues by Ferrate(VI). PLoS ONE 8(2): e55729. doi:10.1371/journal.pone.0055729

Editor: Zhi Zhou, National University of Singapore, Singapore

Received November 4, 2012; Accepted December 29, 2012; Published February 7, 2013

Copyright: (c) 2013 Jiang, Zhou. This is an open-access article distributed under the terms of the Creative Commons Attribution License, which permits unrestricted use, distribution, and reproduction in any medium, provided the original author and source are credited.

Funding: The authors thank the Glasgow Caledonian University Research Committee for offering a research studentship to ZZ for his PhD study. The funders had no role in study design, data collection and analysis, decision to publish, or preparation of the manuscript.

Competing Interests: The authors have declared that no competing interests exist.

*E-mail: jiaqian.jiang@gcu.ac.uk

\section{Introduction}

Pharmaceuticals such as antibiotics, anti-inflammatory drugs, $\beta$ blockers and X-ray contrast media are widely used in our daily life. These pharmaceuticals and their metabolites cannot be fully utilized by human beings or animals and are inevitably emitted into the waters by execration [1-4] and/or through the discharge of industry effluents and hospitals waste waters [5,6]. Results of toxicology studies have revealed that some pharmaceuticals are suspected to have direct toxicity to certain aquatic organisms [7-9] and they could accumulate slowly, and finally lead to irreversible change on wildlife and human beings [10]. The adverse environmental and human health effects could take place under a very low concentration range; from several $\mu \mathrm{g} / \mathrm{l}$ to $\mathrm{ng} / \mathrm{L}$. Due to this, pharmaceutical and personal care products (PPCPs) and endocrine disrupting chemicals (EDCs) are classified as emerging micro-pollutants which have been a significant issue of environmental and public health concern.

The presence of emerging micro pollutants and their potential toxicity are challenge to the global water industries as there is no unit process specifically designed to remove these pollutants; activated sludge and secondary sedimentation in most wastewater treatment works (WWTWs) seems to be inefficient to eliminate them [1 1-15]. Thus, a number of recent studies have been carried out to explore suitable technologies to treat pharmaceutical residuals from water and wastewater. Ozonation was found to be effective to remove pharmaceuticals in municipal WWTWs [16]. Nanofiltration (NF) and reverse osmosis $(\mathrm{RO})$ membrane filtration have been applied at bench, pilot and full scale [17]. Activated carbon adsorption [18] has also been proved as an efficient process to remove pharmaceuticals; addition of $5 \mathrm{mg} / \mathrm{L}$ of powder activated carbon with a 4-h contact time removed $50 \%$ to $>98 \%$ of the volatile PPCPs and $10 \%$ to $>95 \%$ of the polar PPCPs [19].

Another promising technique which can address the concerns on pharmaceutical residues is ferrate $(\mathrm{VI})\left(\mathrm{Fe}^{\mathrm{VI}} \mathrm{O}_{4}{ }^{2-}, \mathrm{Fe}(\mathrm{VI})\right)$. Ferrate (VI) exhibits many advantages because of its dual function as an oxidant and a coagulant [20-24] and it has green chemical properties [25]. Ferrate therefore has been successfully applied into water remediation processes [26-30] and oxidation of carbohydrates [31] and nitrogen-containing pollutants [32]. And researches on the removal of pharmaceuticals and other micro pollutants by ferrate (VI) have been conducted recently (e.g., [33-38]). Moreover, ferrate (VI) is capable of removing more than $85 \%$ of various micropollutants containing electron-rich moieties (ERM) [39].

This paper aims to address the issue of the performance optimisation of pharmaceutical treatment by ferrate (VI). The dose of ferrate, test water $\mathrm{pHs}$ and the physical and chemical properties of pharmaceuticals are major factors to influence the overall treatment efficiency and these were studied in this work. 


\section{Materials and Methods}

\section{Chemicals and Reagents}

Ciprofloxacin (98\%, HPLC grade), ibuprofen (98\%, GC grade), ibuprofen sodium salt (IBU-Na) and potassium ferrate (VI) $(>90 \%)$ were purchased from Sigma-Aldrich; ciprofloxacin hydrochloride BioChemica $(\mathrm{CIP} \cdot \mathrm{HCl})$ was purchased from VWR; other chemicals and reagents used were obtained from Fisher Scientific. All chemicals and reagents were used without further purification. Deionised water used was generated by Elgacan B114 deioniser.

\section{Ferrate Working Solution and Model Test Solution}

The ferrate $(\mathrm{VI})$ working solution $(1 \mathrm{~g} / \mathrm{L})$ was prepared by the addition of solid $\mathrm{K}_{2} \mathrm{FeO}_{4}$ to $0.005 \mathrm{M} \mathrm{Na}_{2} \mathrm{HPO}_{4} / 0.001 \mathrm{M}$ borate buffer solution at $\mathrm{pH} 9.0$, the $\mathrm{pH}$ at which the ferrate solutions are most stable [40].

Both CIP and IBU stock solutions were prepared separately in deionised water with the concentration of $10 \mathrm{mg} / \mathrm{L}$. Several types of model test solution samples (Table 1) were prepared by the dilution of stock solutions to $1 \mathrm{~L}$ with tap water, with the solution $\mathrm{pH}$ (6.8-7.3) unadjusted before dosing ferrate (VI).

\section{Real Wastewater Effluents and Target Pharmaceuticals}

The wastewater samples were taken from the second sedimentation effluent at Shieldhall WWTW, Glasgow, and the major properties of the samples were $\mathrm{COD}=35 \mathrm{mg} / \mathrm{L}$, turbidity $=2 \mathrm{NTU}$ and $\mathrm{pH}$ was 7.37 .

Two litres of raw samples were analysed for pharmaceutical concentrations, and the sample was then spiked with selected pharmaceuticals; each with concentration of $10 \mu \mathrm{g} / \mathrm{L}$. The spiked pharmaceuticals are as follows, 1) $X$-ray contrast media: Iopamidol, Ammonium diatrizoate; 2) Antibiotics: Ciprofloxacin, Sulphamethoxazole, $\mathrm{N}$-acetyl sulphamethoxazole, Erythromycin- $\mathrm{H}_{2} \mathrm{O}$; 3) Non-steroidal anti-inflammatory druds (NSAID): Naproxen, Ibuprofen; 4) $\beta$-blockers: Atenolol; 5) Antineoplasic: Cyclophosphamide, Ifosfamide; 6) Antiepileptics: Carbamazepine; 7) Blood Lipid Lowering: Bezafibrate and 8) Local anesthetic: Lidocaine.

\section{Jar Test}

A series of jar test experiments was carried out with a six-unit stirrer (Kemiraflocculator 2000, Kemwater) under the following protocol: fast mixing for $1 \mathrm{~min}$ at $400 \mathrm{rpm}$; slow mixing for $20 \mathrm{~min}$ at $40 \mathrm{rpm}$; and then sedimentation for $60 \mathrm{~min}$. The ferrate dose applied was $0-4 \mathrm{mg} / \mathrm{L}$ as $\mathrm{Fe}$, and $\mathrm{pH}$ of solutions was adjusted by $0.1 \mathrm{M} \mathrm{H}_{2} \mathrm{SO}_{4}$ or $0.05 \mathrm{M} \mathrm{NaOH}$ to 7.0-7.5. All experiments were duplicated. For the real wastewater effluents, the jar test protocol was the same as the above stated but ferrate dose sued was $0,1,2,3$, 4 , and $5 \mathrm{mg} / \mathrm{L}$ as Fe and working $\mathrm{pH}$ was $\mathrm{pH} 6$ and 8.

Table 1. Model test solutions and their specific analytical methods.

\begin{tabular}{lll}
\hline No & Model water samples & Analytical methods \\
\hline 1 & $100 \mu \mathrm{g} / \mathrm{L} \mathrm{IBU}$ & Oasis HLB SPE+LC-MS \\
2 & $10 \mu \mathrm{g} / \mathrm{L} \mathrm{IBU}$ & Oasis HLB SPE+LC-MS \\
3 & $100 \mu \mathrm{g} / \mathrm{L} \mathrm{CIP}$ & Strata-X SPE+UV/Vis \\
4 & $10 \mu \mathrm{g} / \mathrm{L} \mathrm{CIP}$ & Strata-X SPE+HPLC-UV \\
5 & $10 \mu \mathrm{g} / \mathrm{L} \mathrm{IBU}+10 \mu \mathrm{g} / \mathrm{L} \mathrm{CIP}$ & Strata-X SPE+HPLC-UV \\
\hline doi:10.1371/journal.pone.0055729.t001 &
\end{tabular}

\section{Analytical Methods}

As shown in Table 1, three analytical methods were employed for different model test samples. Specifically, for model test solution containing IBU only, solid phase extraction (SPE, Oasis HLB cartridges)+liquid chromatography (LG)-mass spectrometry (MS) was employed, which was conducted in the analytical lab of Bodensee-Wasserversorgung (BWV), Germany. In addition, a simple analytical method, SPE+UV/Vis spectrophotometry, was applied to $100 \mu \mathrm{g} / \mathrm{L}$ CIP model water samples. Moreover, for $10 \mu \mathrm{g} / \mathrm{L}$ CIP and mixed $10 \mu \mathrm{g} / \mathrm{L}$ IBU\&CIP water samples, SPE+high performance liquid chromatography (HPLC)-UV was proposed.

Solid phase extraction. The treated model test solution samples were filtered through $0.45 \mu \mathrm{m}$ cellulose nitrate membrane filters (Milipore) and then enriched by solid phase extraction (SPE). Two types of SPE cartridges were employed in the experiment: Strata-X (200 mg/6 mL and $1 \mathrm{~g} / 20 \mathrm{~mL}$, from Phenomenex) and Oasis HLB (3 mL/60 mg, from Waters USA). Oasis HLB cartridges were only used for those model water samples containing IBU only. Generally, for Strata-X $200 \mathrm{mg} / 6 \mathrm{~mL}$ cartridges, the extraction method was: (1) condition: $4 \mathrm{~mL}$ methanol $(\mathrm{MeOH})$; (2) equilibrate: $4 \mathrm{~mL}$ deionised water; (3) loading samples: desired amount of model water samples under vacuum at a flow rate of $5-10 \mathrm{~mL} / \mathrm{min}$; (4) wash: $2 \mathrm{~mL}$ 50:50 (v/v) $\mathrm{MeOH} / \mathrm{H}_{2} \mathrm{O}$; (5) dry: 15 min under gentle nitrogen flow; and (6) elute: $2 \times 2 \mathrm{~mL} \mathrm{2:49:49} \mathrm{(v/v/v)} \mathrm{formic} \mathrm{acid/MeOH/}$ ACN. Elutes were either re-constituted to $5 \mathrm{~mL}$ for $\mathrm{UV} / \mathrm{V}$ is spectrophotometric measurement or dried down to $1 \mathrm{~mL}$ for HPLC-UV detection.

On the other hand, IBU only model test solutions were extracted by Oasis HLB cartridges with the use of SPE preparation system Gilson GX-271 ASPEC. The programmed SPE procedure was as follows: (1) condition: $3 \mathrm{~mL}$ methanol and $3 \mathrm{~mL} \mathrm{H} \mathrm{H}_{2} \mathrm{O}$; (2) loading samples: desired amount of water samples at $10 \mathrm{~mL} / \mathrm{min}$; (3) wash: $0.5 \mathrm{~mL}$ water; (4) dry: 10 min under a gentle stream of nitrogen gas; and (5) elute: $2 \times 2 \mathrm{~mL}$ methanol. Then, samples elutes were evaporated to less than $1 \mathrm{~mL}$ using nitrogen gas by Barkey sample evaporation system (Barkey, Germany), and reconstituted with methanol to $1 \mathrm{~mL}$ for LC/ MS analysis. Prior to extraction, selected samples were spiked with $25 \mu \mathrm{L}$ of thidiazuron solution $(20 \mathrm{ng} / \mu \mathrm{L})$ as an internal standard.

For the real wastewater treatment, the samples were filtered by $1.2 \mu \mathrm{m}$ glass fibre filter papers (Fisher), the filtrates were then filtered by $0.45 \mu \mathrm{m}$ membrane filters (Milipore). The Tandem SPE cartridges used were Strata-X $1 \mathrm{~g} / 12 \mathrm{~mL}+\mathrm{ENV}+500 \mathrm{mg} /$ $6 \mathrm{~mL}$, and the extraction procedures were: 1)Adjusted the $\mathrm{pH}$ of solution to 2 by $2 \mathrm{M} \mathrm{H}_{2} \mathrm{SO}_{4}$, spiked with $1 \mathrm{~mL}$ deuterated internal standards; 2) $10 \mathrm{~mL}$ methanol $+10 \mathrm{~mL}$ water were added for the conditioning; 3) flow rate was $10 \mathrm{~mL} / \mathrm{min}$ for loading samples; 4) $10 \mathrm{~mL}$ water was used for washing samples and 5) Drying the cartridges under $\mathrm{N}_{2}$ flow. After extraction, the SPE cartridges were labelled and kept in the freezer for future elution.

The elution was conducted on a Phenomenex SPE 24-position vacuum manifold. The solvents used for the elution are shown in Table 2, and all fractions are collected in silanised vials, combined and dried down at $50^{\circ} \mathrm{C}$ under a stream of $\mathrm{N}_{2}$.

UV/Vis spectrophotometry. The concentrations of CIP in the 5-mL Strata-X SPE elutes could be measured by a UV/Vis spectrophotometer (Jenway 6505 with $10 \mathrm{~mm}$ light-path) at the wavelength of $280 \mathrm{~nm}$. A six-point calibration curve was generated based on absorption of standard CIP solutions in 2:49:49 (v/v/v) formic acid/MeOH/ACN at $280 \mathrm{~nm}$. Concentrations of CIP in model wastewater samples were calculated based on the absorbance reading and the established calibration curve [41]. 
Table 2. The solvents used for the elution.

\begin{tabular}{lll}
\hline Cartridge & Water & $\mathbf{0 . 1 \%}$ Formic acid in ACN/MeOH (50/50) \\
\hline Strata-X & $3 \times 4 \mathrm{ml}$ & $4 \times 4 \mathrm{ml}$ \\
ENV + & $3 \times 2 \mathrm{ml}$ & $4 \times 2 \mathrm{ml}$ \\
\hline doi:10.1371/journal.pone.0055729.t002
\end{tabular}

HPLG-UV analysis. The HPLG separations were performed on the Agilent 1100 system (Agilent Technologies) consisting of a degasser, a binary pump, a thermostated column oven and a diode array detector (DAD). $50 \mu \mathrm{L}$ of samples was manually injected to a $2.6 \mu \mathrm{m}, 100 \mathrm{~mm} \times 2.10 \mathrm{~mm}$ reversed phase Kinetex $\mathrm{XB}^{-\mathrm{C}_{18}}$ column (Phenomenex). The column was kept at $25^{\circ} \mathrm{C}$ and eluted with $0.1 \%$ formic acid in deionised water and acetonitrile (ACN) at a flow rate of $0.2 \mathrm{~mL} / \mathrm{min}$. The elution started with $20 \%$ ACN and then with a linear gradient from $20 \%$ to $30 \%$ ACN over the next $3 \mathrm{~min}$. Then the percentage of ACN was raised to $55 \%$ in $2 \mathrm{~min}$, held at this percentage for $9 \mathrm{~min}$ and finally lowered to $20 \%$ in $1 \mathrm{~min}$. Before the next injection, the system was allowed to equilibrate for $10 \mathrm{~min}$. The DAD wavelengths for IBU and CIP detection were set at $220 \mathrm{~nm}$ and $280 \mathrm{~nm}$, respectively.

LG-MS analysis. The LC-MS instrument employed to analyse IBU was Acquity LCT Premier XE system which consists of ACQUITY ultra performance liquid chromatography (UPLC) and orthogonal acceleration time-of-flight (oa-TOF) mass spectrometer (MS) (Waters, USA). The UPLC contained ACQUITY UPLC High Strength Silica (HSS) T3 Column $(100 \mathrm{~mm} \times 2.1 \mathrm{~mm}, 1.7 \mu \mathrm{m}$ particles, Waters, USA). The mobile phase was a mixture of two solvents (Solvent A: $0.1 \%$ formic acid in water; solvent B: $0.1 \%$ formic acid in $\mathrm{ACN}$ ). For the analysis of IBU, the elution of the column started from initially $5 \% \mathrm{~B}$, then a with a linear gradient increased to $90 \%$ B over the course of $7 \mathrm{~min}$, then consistent till $8 \mathrm{~min}$, and finally lowered back to $5 \% \mathrm{~B}$ at $8.1 \mathrm{~min}$. The injection volume of sample was $250 \mu \mathrm{L}$, with the running time of $10 \mathrm{~min}$ and a flow rate of $0.3 \mathrm{~mL} / \mathrm{min}$. After LC separation, the MS analyser for IBU was ESI- mode, with the following parameters: capillary $1823.0 \mathrm{~V}$, sample cone $30.0 \mathrm{~V}$, desolvation temperature $350.0^{\circ} \mathrm{C}$, source temp $150.0^{\circ} \mathrm{C}$, and MCP detector $2600.0 \mathrm{~V}$. Parent ions $\left(\mathrm{MH}^{-}\right)$were monitored at $\mathrm{m} / \mathrm{z} 221.0497$.

\section{Results and Discussion}

\section{Analytical Methods}

HPLC-UV. IBU and CIP were separated with a $\mathrm{G}_{18}$ column. The gradient elution of the column presented a clear separation of both chemicals in $15 \mathrm{~min}$. CIP was eluted firstly from the column with a retention time $9.5 \mathrm{~min}$. The signal of IBU at $220 \mathrm{~nm}$ showed a decreasing trend from $5 \mathrm{~min}$ and went flat again at $10.5 \mathrm{~min}$. This phenomenon might be caused by the instrumental response to the elution gradient. However, the bulk of IBU came out at around $12.7 \mathrm{~min}$, which was not affected by the previous decreasing signal.

The calibration of IBU and CIP were carried out simultaneously with standard solutions containing IBU and CIP. The curve covered the concentration range of $0.5-6 \mathrm{mg} / \mathrm{l}$, and was conducted four times. The IBU calibration equation with the linear regression is $y=80.18 x+0.05$, where $x$ means the concentration of IBU and y means the response of instrument, with a coefficient of correlation $\left(r^{2}\right)$ 0.997. In terms of CIP, an equation $y=28.11 x-4.35$ could fit the seven-point calibration well with the coefficient of correlation $\left(r^{2}\right) 0.998$.

Recovery studies of standard solutions $(\mathrm{n}=4)$ showed $78.0 \pm 14.7 \%$ of CIP and $139.1 \pm 2.2 \%$ of IBU recovered by the instrument, respectively.

LG-MS. A seven-point calibration curve for the concentration range of $0.04-1.2 \mathrm{mg} / \mathrm{L}$ was generated based on MS response of standard IBU solutions in methanol. Quantification of IBU was based on the response at $\mathrm{m} / \mathrm{z} 221.0497\left(\mathrm{MH}^{-}\right)$vs. linear regression equation $\mathrm{y}=57.76 \mathrm{x}$, where $\mathrm{x}$ means the concentration of IBU and $y$ means the response of the instrument, with the coefficient of correlation 0.998 . Recovery was obtained by running standard IBU solutions $(5 \mu \mathrm{g} / \mathrm{L})$ through SPE and LC-MS process, with the mean recovery $117.7 \pm 30.6 \%(n=4)$.

\section{Single Compound with Initial Concentration $100 \mu \mathrm{g} / \mathrm{L}$}

For CIP samples with initial concentration of $100 \mu \mathrm{g} / \mathrm{L}$, average $60 \%$ of CIP was removed from the model wastewater with a low ferrate (VI) dose ranging from 0.02 to $0.34 \mathrm{mg} / \mathrm{L}$ as Fe (Fig. 1). As increasing the dose of ferrate (VI), slight improvement in the removal efficiency was observed, from $61.2 \%$ at $0.02 \mathrm{mg}$ $\mathrm{Fe} / \mathrm{L}$ to $68.9 \%$ at $0.34 \mathrm{mg} \mathrm{Fe} / \mathrm{L}$. The average removal efficiency dropped dramatically to $53.0 \%$ at dose of $0.25 \mathrm{mg} / \mathrm{L}$ as Fe may be caused by the analytical deviation. Though the overall removal of CIP at this dose range was less than $70 \%$, the benefits of using ferrate were apparent in that low ferrate doses (maximum $0.34 \mathrm{mg} / \mathrm{L}$ as $\mathrm{Fe}$ ) can remove up to $69 \%$ of CIP.

Further studies were carried out to investigate if relatively high ferrate doses could improve CIP removal. Figures 1 and 2 show that over $80 \%$ of CIP can be removed if the ferrate dose reached or exceeded $1 \mathrm{mg} / \mathrm{L}$ as Fe. This is consistent with that from a preliminary study [42] where a small dose of ferrate (up to $1 \mathrm{mg}$ / $\mathrm{L}$ as $\mathrm{Fe}$ ) can remove more than $80 \%$ of CIP and residual concentration could be lower than $1 \mu \mathrm{g} / \mathrm{L}$.

However, the treating performance of IBU by ferrate (VI) was not as good as that of CIP, less than $25 \%$ of IBU was removed from the model water when dosed ferrate $(\mathrm{VI})$ was $0.5-4 \mathrm{mg} \mathrm{Fe} / \mathrm{L}$ (Fig. 2). The highest removal of IBU happened at the dosage $3 \mathrm{mg} / \mathrm{L}$ as $\mathrm{Fe}$, where $21.0 \pm 4.9 \%$ of IBU was degraded.

\section{Single Compound with Initial Concentration $10 \mu \mathrm{g} / \mathrm{L}$}

Compared with the case of $100 \mu \mathrm{g} / \mathrm{L}$ CIP model test solutions, when the initial concentration was $10 \mu \mathrm{g} / \mathrm{L}$, the overall treating performance of CIP by ferrate (VI) decreased to less than $60 \%$ (Fig. 3). Specifically, when the ferrate (VI) doses were $0.5-2.5 \mathrm{mg}$ $\mathrm{Fe} / \mathrm{L}$, the CIP removal efficiencies were between $25 \%$ and $60 \%$, with a highest removal $55.5 \pm 1.2 \%$ at the dose of $2.0 \mathrm{mg} / \mathrm{L}$ as Fe.

On the other hand, the overall treating performance of IBU improved when the initial concentration was $10 \mu \mathrm{g} / \mathrm{L}$. As shown in Fig. 3, the IBU removal at ferrate dose $0.5 \mathrm{mg} \mathrm{Fe} / \mathrm{L}$ was $11.2 \%$, which was similar to the situation when the initial IBU was $100 \mu \mathrm{g} / \mathrm{L}$. Raising ferrate dose improved the IBU removal. When the dose was over $1.5 \mathrm{mg} / \mathrm{L}$ as Fe, the IBU removal could exceed $25 \%$, with the maximum IBU removal of $40 \%$ for an optimum dose, $1.5 \mathrm{mg} \mathrm{Fe} / \mathrm{L}$.

\section{Mixed IBU\&CIP}

Further study was carried out to investigate the treating performance of mixed IBU and CIP model test solutions by ferrate. The initial concentrations of both compounds were $10 \mu \mathrm{g}$ / $\mathrm{L}$, and the ferrate doses applied were $0.5-2.5 \mathrm{mg} / \mathrm{L}$. Results show that ferrate salts possess more capability to remove CIP than IBU (Fig. 4). Averagely, at each dose, ferrate removed CIP around 10\% more than IBU. The overall removal of IBU was less than $15 \%$, 


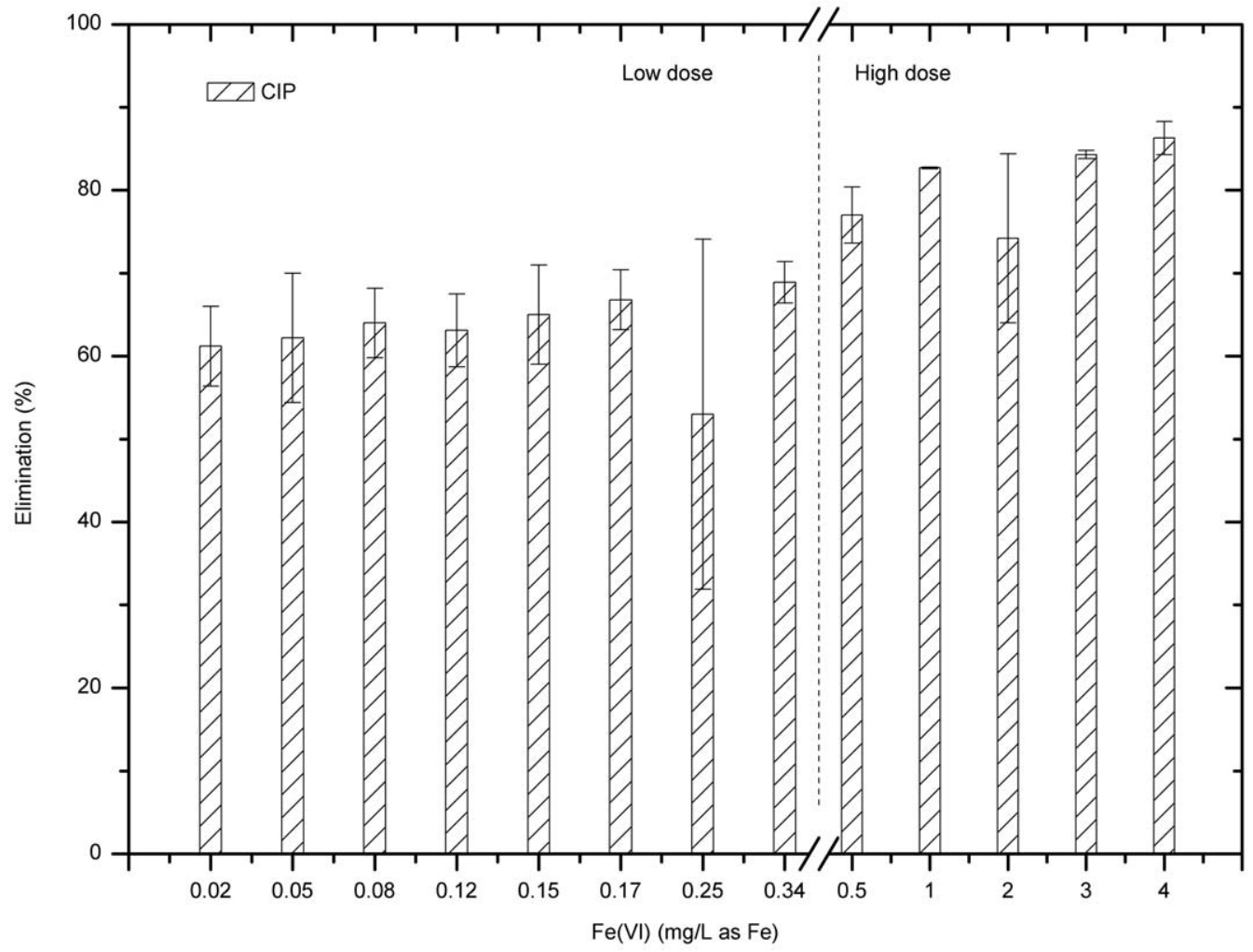

Figure 1. CIP removal by low doses and relatively high doses of ferrate (VI). doi:10.1371/journal.pone.0055729.g001

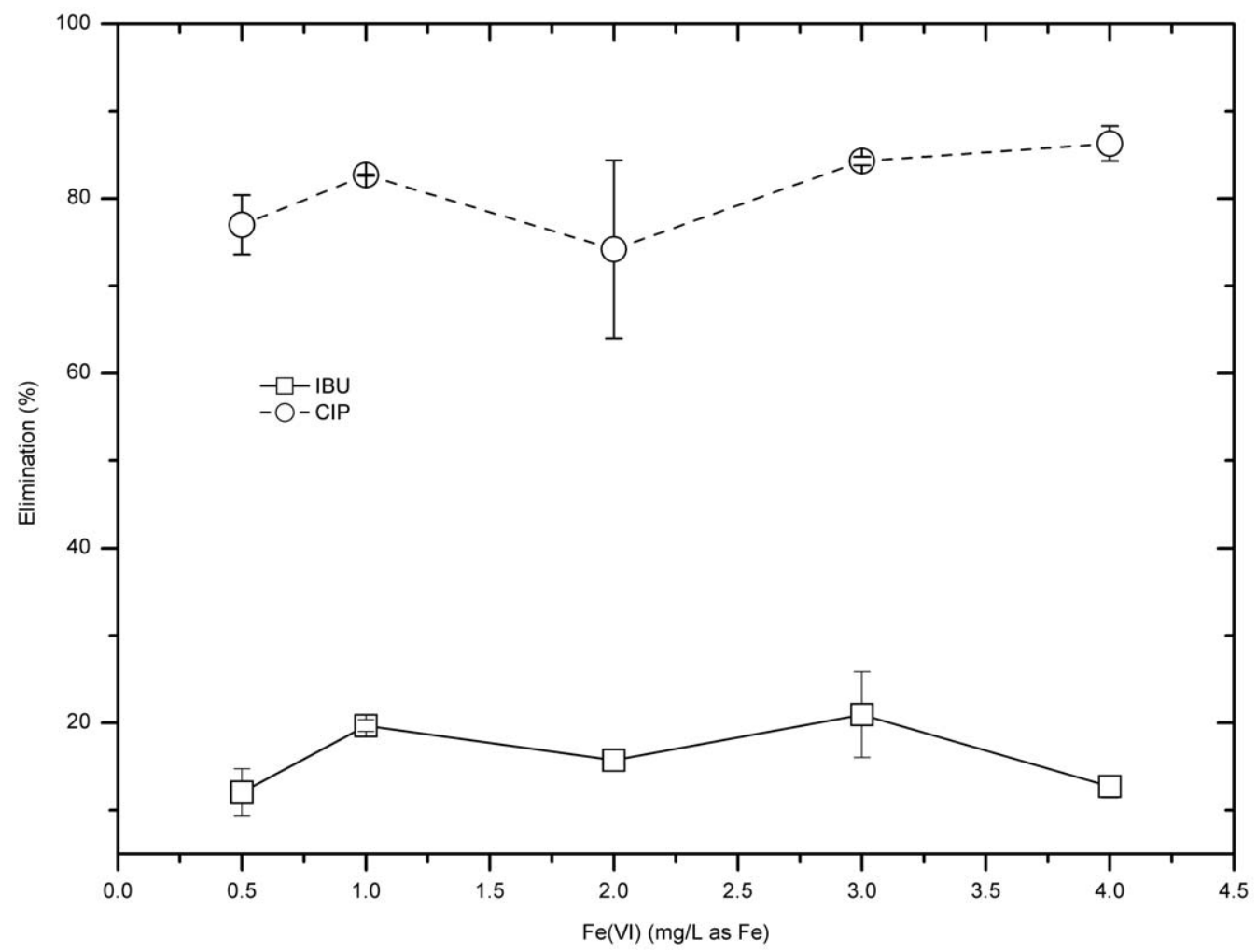

Figure 2. IBU and CIP removal by ferrate (VI) doses of $0.5-4 \mathrm{mg} / \mathrm{L}$ as Fe. doi:10.1371/journal.pone.0055729.g002 


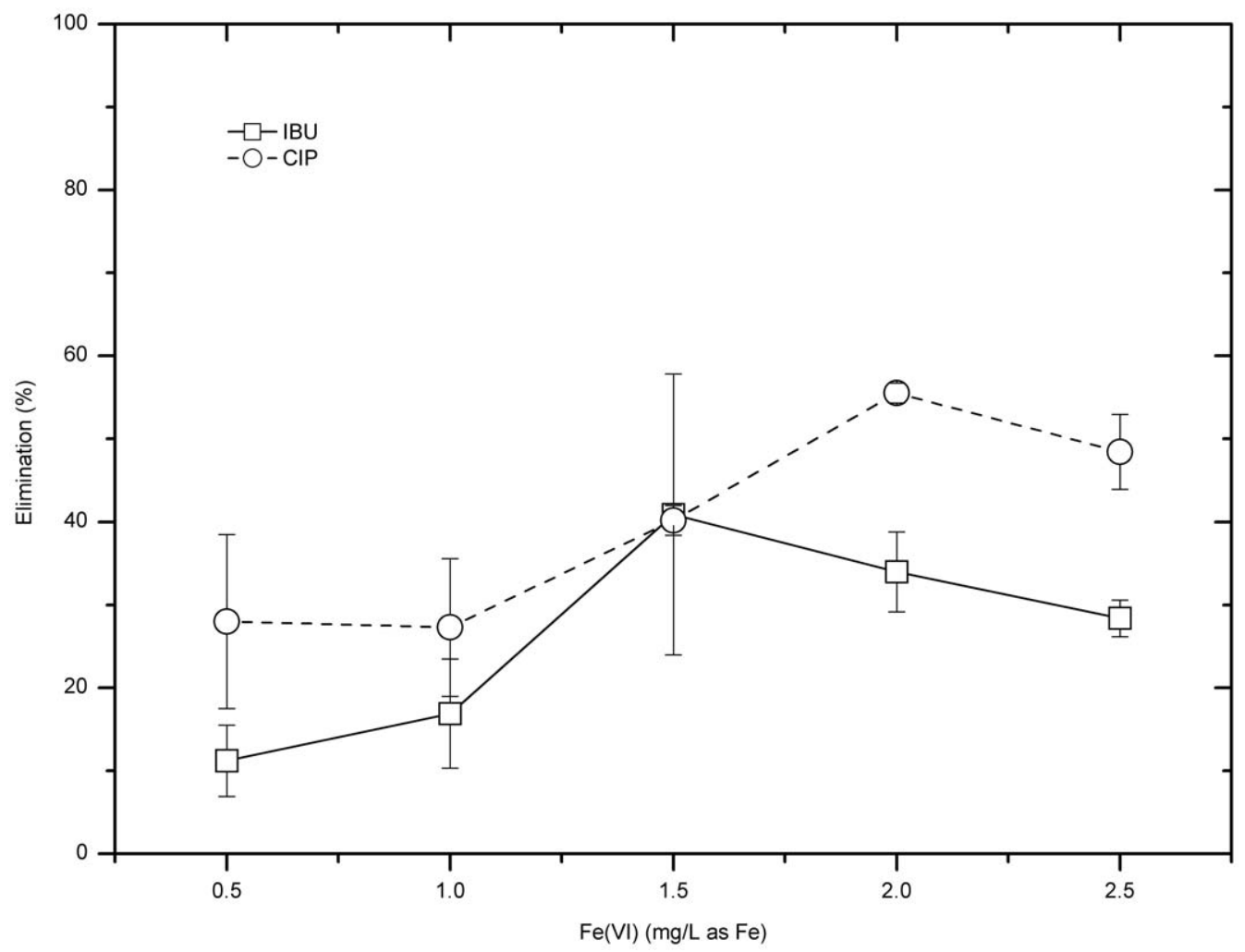

Figure 3. Treatment of $10 \mu \mathrm{g} / \mathrm{L}$ IBU model water samples by ferrate (VI) $(\mathrm{pH}=\mathbf{7 . 0 5} \pm \mathbf{0 . 2 5}$ ). doi:10.1371/journal.pone.0055729.g003

with the highest removal efficiency $15.2 \pm 1.8 \%$ at dose $2.0 \mathrm{mg} / \mathrm{L}$ as Fe. The treatment of CIP was improved by increasing the ferrate dose; when the dose increased to $2.5 \mathrm{mg} \mathrm{Fe} / \mathrm{L}$, the CIP removal increased to $31.1 \pm 6.6 \%$.

Fig. 5 gives the comparison of the pharmaceutical removal among different model test solutions. Generally, the treating performance of samples with single compound was better than those with both compounds. For instance, at each dose, the CIP removal of samples with single compound was $7-30 \%$ higher than that of samples with both compounds. The biggest gap happened at dose $2.0 \mathrm{mg} / \mathrm{L}$, where CIP removal for CIP only samples was $55.5 \pm 1.2 \%$ while for mixed samples was only $25.9 \pm 3.4 \%$. In the case of IBU, the IBU removal in the IBU alone solutions was 5$35 \%$ higher than that of in the mixing IBU and CIP solutions.

Ferrate (VI) has shown much more capability in the degradation of CIP than that of IBU. This can be explained that CIP belongs to electron-rich organic moieties (EOM) which can be easily transformed during ferrate oxidation. However, the carboxylic group in IBU is an electron-withdrawing group with which the reactivity of ferrate is usually slow $[35,43]$.

\section{pH Dependence}

Preliminary studies showed that comparing with initial $\mathrm{pH}$, final solution $\mathrm{pH}$ after dosing ferrate has much more influence on the removal of CIP and IBU. As shown in Fig. 6, IBU removal showed great difference between $\mathrm{pH} 4$ and $\mathrm{pH} 10$. At $\mathrm{pH} 4$, for all three doses of ferrate, IBU removal was much higher than other $\mathrm{pH}$ conditions, with over $50 \%$ IBU removal for the dose of $1 \mathrm{mg} / \mathrm{L}$ or $2 \mathrm{mg} / \mathrm{L}$. However, for nearly all samples with final $\mathrm{pH}$ over 4 , IBU removal was below $30 \%$. As shown in Figure 7, for all ferrate doses, the CIP removal efficiencies of samples with final $\mathrm{pH}$ between 4 and 8 were above $45 \%$ and were much higher than those of final $\mathrm{pH} 9$ and 10 (less than 25\% CIP removal).

The effect of final solution $\mathrm{pH}$ on the IBU or CIP removal might be understood by considering compounds $p K a$ values. The $p K a$ of IBU is 4.91 , therefore when the $\mathrm{pH}$ was $<5$, the major species would be IBU, which was relatively easy to be oxidised. For CIP, its $\mathrm{pKa}$ is 6.09 and 8.2, respectively, and when the $\mathrm{pH}$ of solution was $>8$, the major species of CIP would be dissociated $\mathrm{CIP}^{-}{ }^{-}$, which was relatively difficult to be oxidised [38], and this leads to an overall decrease in CIP removal efficiency. Strong $\mathrm{pH}$ dependence of removal efficiency of IBU and CIP was also observed by other researchers. The reaction rate constant of ferrate (VI) versus ibuprofen (IBU) was $0.3 \mathrm{M}^{-1} \mathrm{~s}^{-1}$ at $\mathrm{pH} 7.5$ then slipped sharply to $0.01 \mathrm{M}^{-1} \mathrm{~s}^{-1}$ at $\mathrm{pH} 9.0$ [43], and the rate constant of ferrate vs. ciprofloxacin (CIP) was over $500 \mathrm{M}^{-1} \mathrm{~s}^{-1}$ at $\mathrm{pH} 6$ but only $10 \mathrm{M}^{-1} \mathrm{~s}^{-1}$ at $\mathrm{pH} 9.5$ [35]. In general, both IBU and CIP belong to electro-rich organic moieties (EOM), which can be potentiaslly transformed during ferrate oxidation and this has been demonstarted in other studies (e.g., [44]).

Strong $\mathrm{pH}$ effect on the IBU and CIP removal by ferrate(VI) can also be considered from ferrate(VI) speciation against solution $\mathrm{pH}$. There are four ferrate(VI) species in aqueous solution that depend on $\mathrm{pH}: \mathrm{H}_{3} \mathrm{FeO}_{4}{ }^{+}, \mathrm{H}_{2} \mathrm{FeO}_{4}, \mathrm{HFeO}_{4}{ }^{-}$, and $\mathrm{FeO}_{4}{ }^{2-}$, and the corresponding dissociation constants are $\mathrm{pK}_{1} 1.6 \pm 0.2, \mathrm{pK}_{2}$ 3.5, and $\mathrm{pK}_{3}$ 7.23, respectively [45]. $\mathrm{FeO}_{4}{ }^{2-}$ is the dominant species in alkaline conditions, and $\mathrm{HFeO}_{4}{ }^{-}$predominates in mildly acidic conditions. Ferrate(VI) has a higher oxidation potential at low $\mathrm{pH}(2.2 \mathrm{~V})$ than in the alkaline condition $(0.72 \mathrm{~V})$ [23] and thus the lower the solution final $\mathrm{pH}$, the stronger oxidation potential of ferrate $(\mathrm{VI})\left(\mathrm{HFeO}_{4}{ }^{-}\right.$predominates $)$ although the stability of ferrate(VI) decreases at low $\mathrm{pH}$ solutions. 


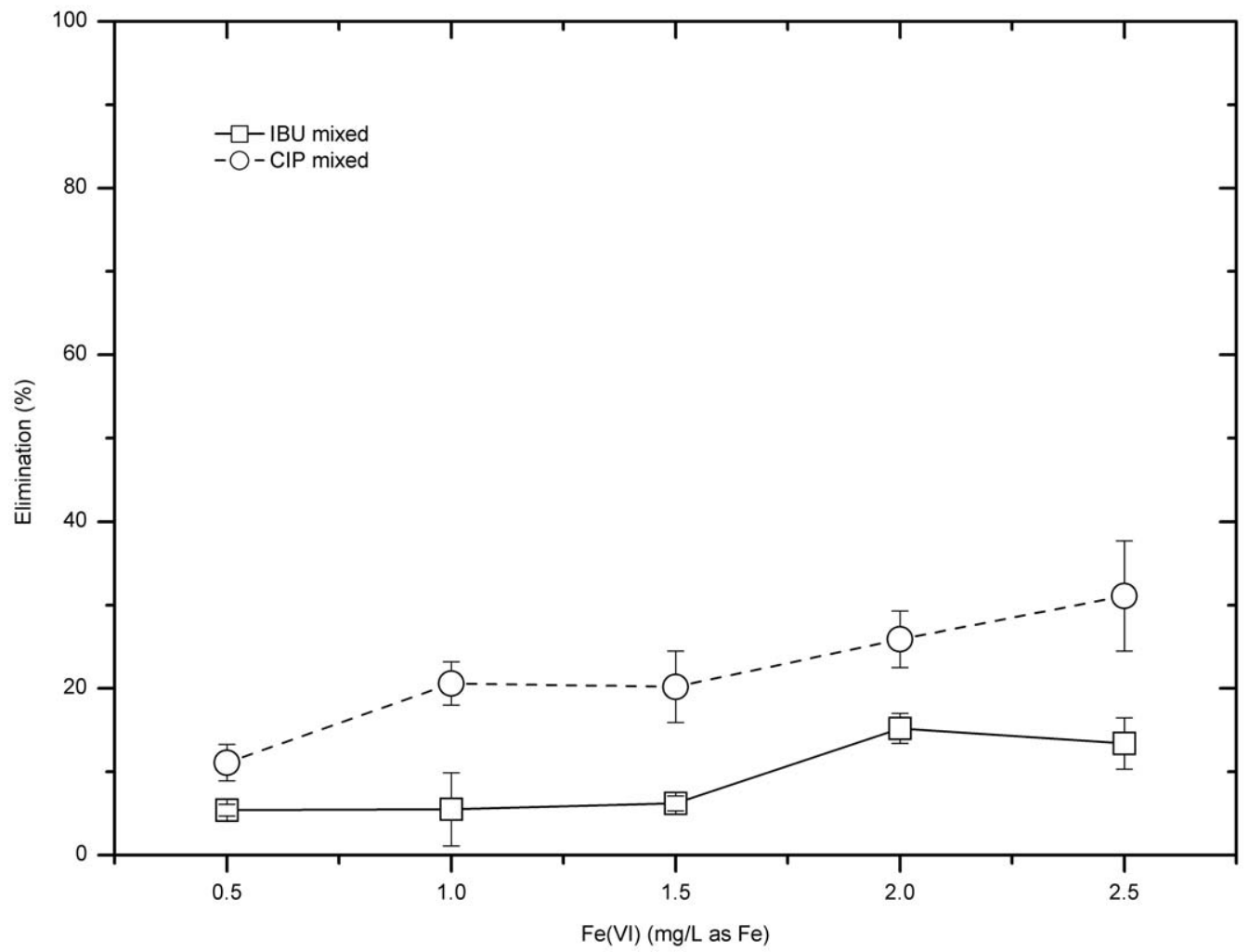

Figure 4. Experimental results of $10 \mu \mathrm{g} / \mathrm{L}$ IBU and CIP mixed model test solutions (pH=7.05 \pm 0.25 ). doi:10.1371/journal.pone.0055729.g004

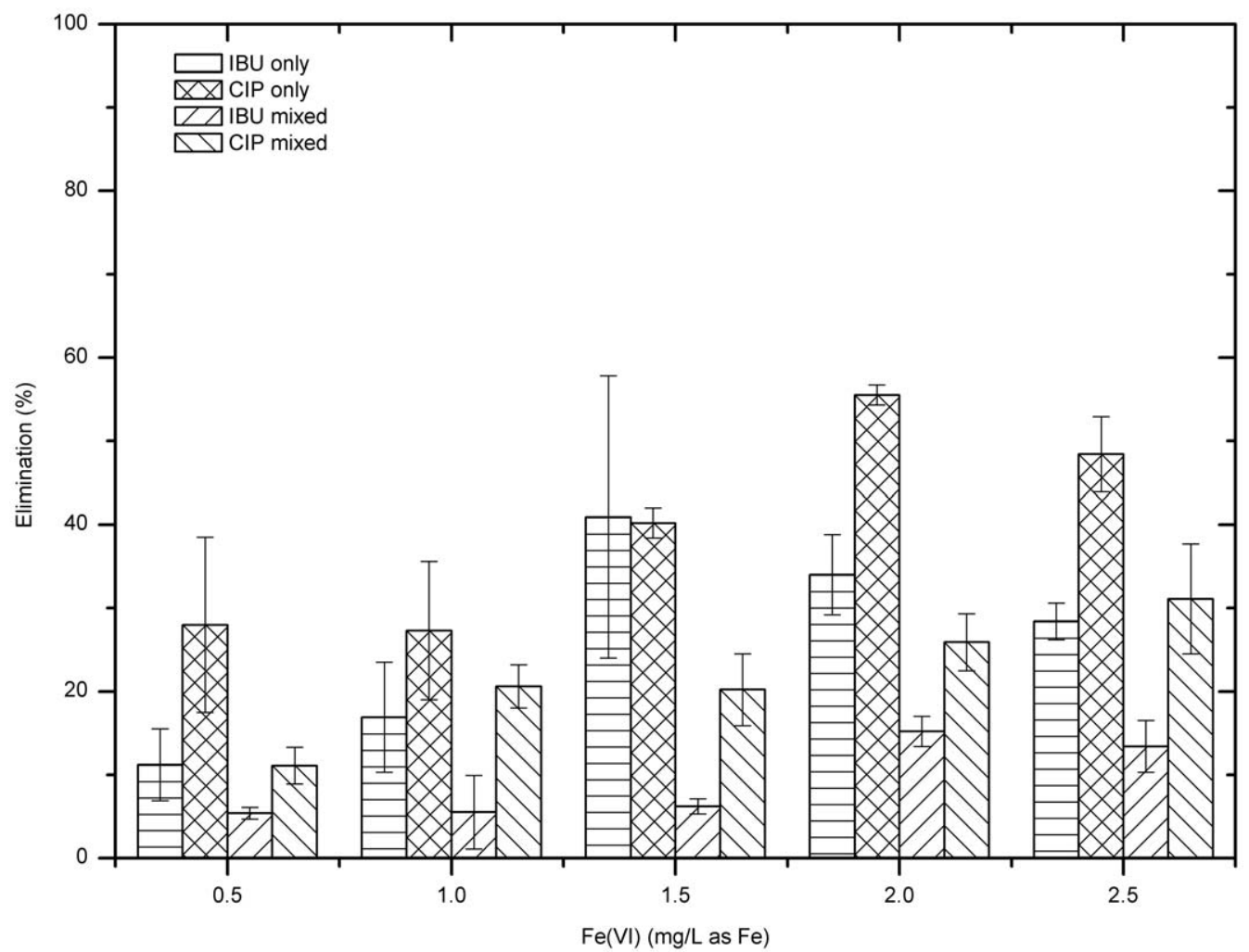

Figure 5. Comparison of the treating performance among different model test solutions $(\mathrm{pH}=7.05 \pm 0.25)$. doi:10.1371/journal.pone.0055729.g005 


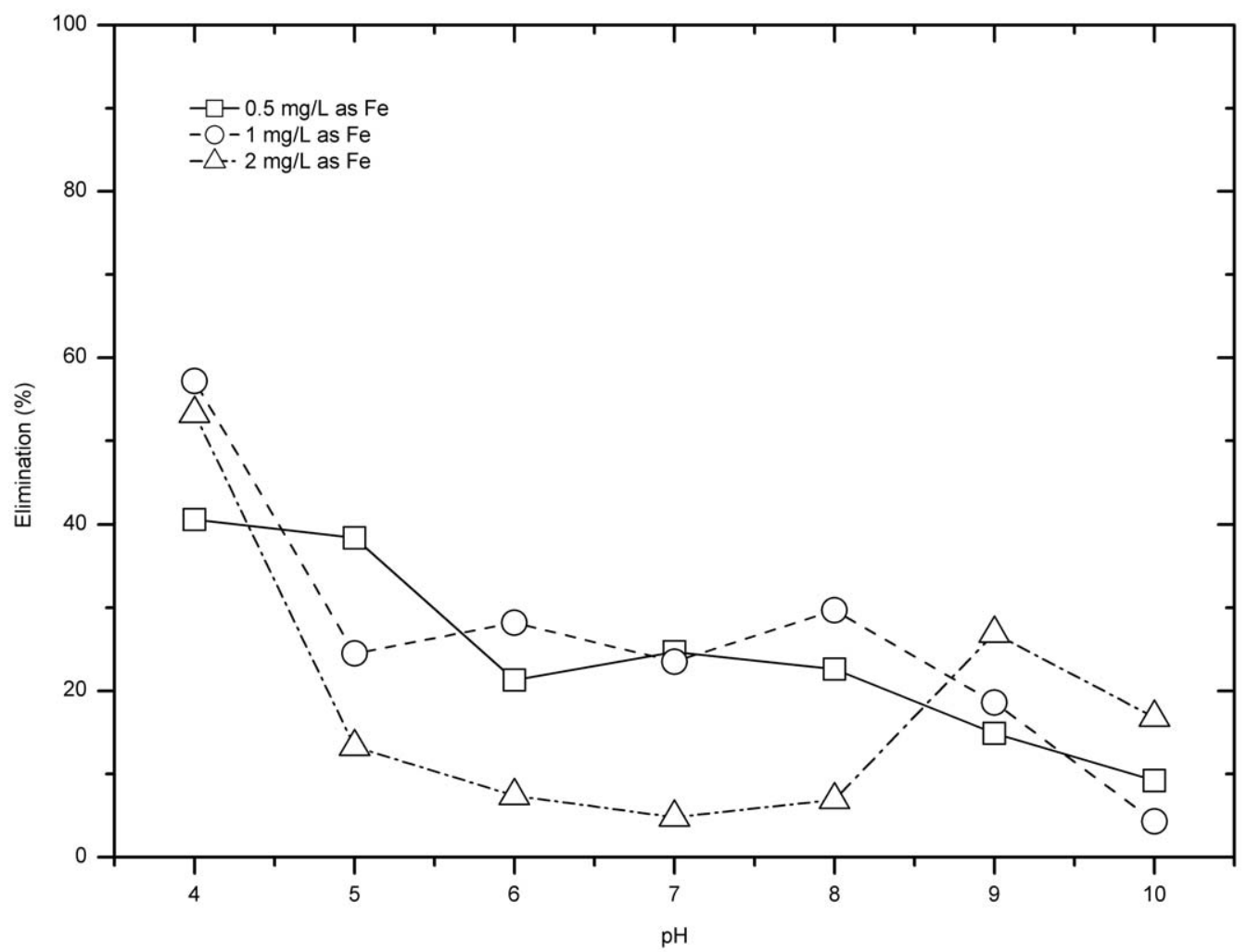

Figure 6. pH dependence of IBU removal by ferrate.

doi:10.1371/journal.pone.0055729.g006

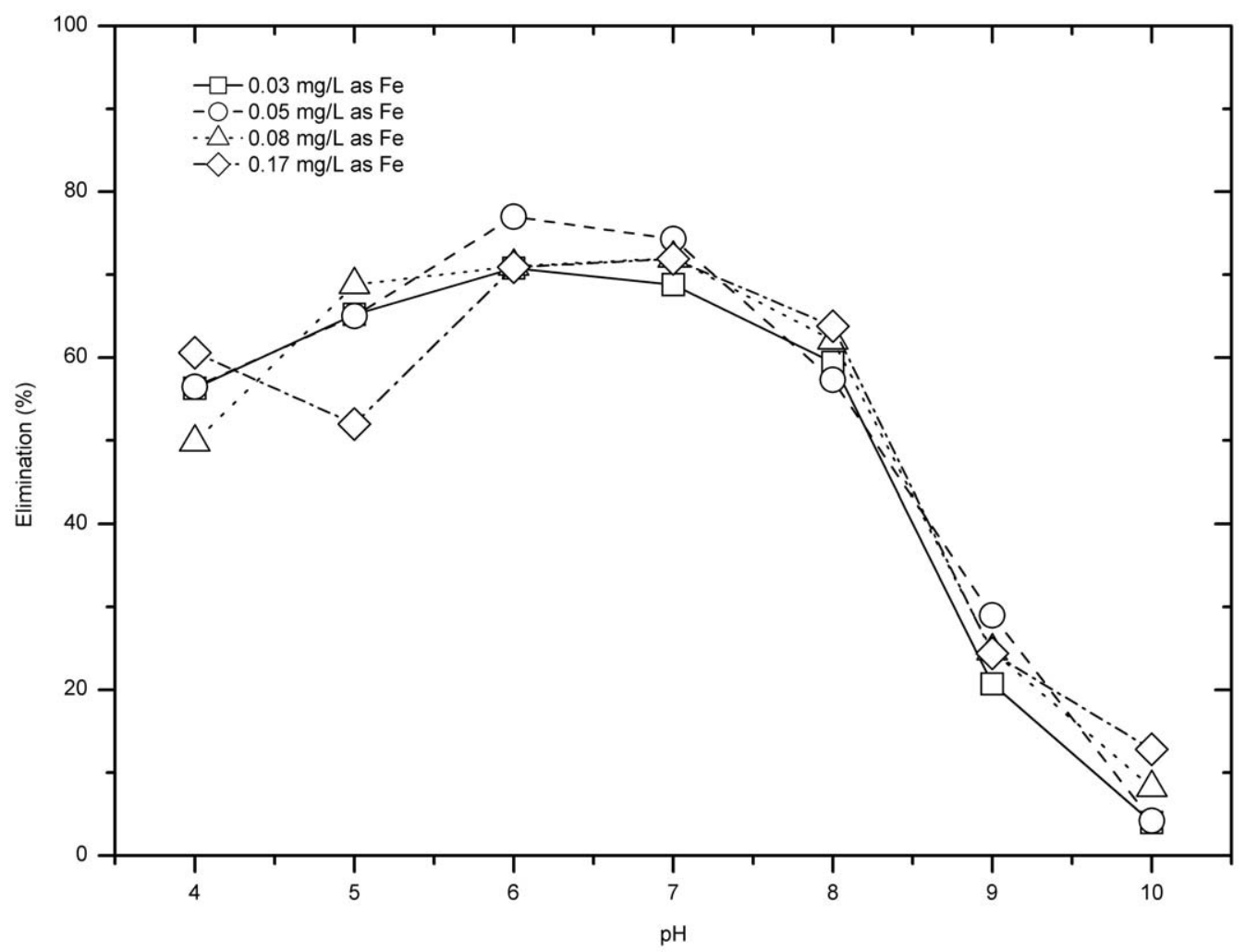

Figure 7. CIP removal of samples with various final $\mathrm{pH}$ for various ferrate doses. doi:10.1371/journal.pone.0055729.g007 


\section{Removal of Selected Pharmaceuticals Spiked in the Final Effluent by Ferrate (VI)}

Occurrence of pharmaceuticals in the raw effluent. Six compounds were detected in the raw effluent samples, with concentrations ranging from 100 to $320 \mathrm{ng} / \mathrm{L}$. The concentrations of naproxen, carbamazepine and atenolol were over $200 \mathrm{ng} / \mathrm{L}$, among which naproxen exhibited the highest concentration with an average concentration $317.3 \mathrm{ng} / \mathrm{L}$. In addition, erythromycin$\mathrm{H}_{2} \mathrm{O}$, lidocaine and bezafibrate were also detected in the effluent, with the concentrations $100-120 \mathrm{ng} / \mathrm{L}$.

Removal of pharmaceuticals at pH 6 and 8. As shown in Fig. 8, except ciprofloxacin and naproxen, the removal efficiencies for other compounds by ferrate were under $25 \%$ in the dosage range when the solution $\mathrm{pH}$ was 6 . As for ciprofloxacin, the removal efficiency showed good linear correlation with the rising ferrate dose, e.g. from $16 \%$ at $1 \mathrm{mg} / \mathrm{L}$ as $\mathrm{Fe}$ to $69 \%$ at $5 \mathrm{mg} / \mathrm{L}$ as $\mathrm{Fe}$.

Removal efficiencies of ciprofloxacin, naproxen and ibuprofen were $20-60 \%$ for ferrate doses $1-5 \mathrm{mg} \mathrm{Fe} / \mathrm{L}$. However, the elimination of n-acetyl sulphamethoxazole was only less than $10 \%$ for any ferrate dose. Besides, except ciprofloxacin and ifosfamide, raising ferrate dose did not improve the pharmaceutical removal significantly. As for ifosfamide and ciprofloxacin, when the ferrate dose was raised from $3 \mathrm{mg} / \mathrm{L}$ to $5 \mathrm{mg} / \mathrm{L}$, the removal efficiency increased from $9 \%$ to $38 \%$ for ifosfamide and from $44 \%$ to $63 \%$ for ciprofloxacin, respectively (Fig. 9).

Fig. 10 shows the pharmaceuticals removal by ferrate when the solution $\mathrm{pH}$ was 8 and ferrate dose was $5 \mathrm{mg} / \mathrm{L}$ as Fe. As shown in the graph, the removal efficiency of ciprofloxacin was the highest among the compounds listed, with an average removal of $63 \%$, followed by naproxen (43\%). On the other hand, n-acetyl sulphamethoxazole was the hardest to remove by ferrate, with an average removal of $8 \%$. The selective removal of pharmaceu- ticals by ferrate(VI), as demonstrated by this study, is consistent with that from other studies [35]. Ferrate(VI) can degrade electron-rich organic moieties [35,39] of pharmaceuticals such as ciprofloxacin and then achieve high percentage removals but difficult to oxidise other pharmaceuticals such as n-acetyl sulphamethoxazole and ibuprofen. Nevertheless, sewage tertiary treatment by ferrate $(\mathrm{VI})$ should achieve the removal of pharmaceuticals and other emerging micro pollutants as well as will enhance the effluent qualities in general such as lower concentrations of suspended solids, phosphate and COD [30].

\section{Conclusions}

Results of treatment of CIP by ferrate show that ferrate can remove at least $60 \%$ of CIP from model test solutions even at very low ferrate doses $(<0.3 \mathrm{mg} / \mathrm{L})$. Besides, increasing ferrate dose up to $1 \mathrm{mg} \mathrm{Fe} / \mathrm{L}$ as $\mathrm{Fe}$ can achieve more than $80 \%$ removal efficiency of CIP. However, ferrate did not show similar treating performance for IBU degradation, with only $30 \%$ IBU removal at ferrate dose of $2 \mathrm{mg} \mathrm{Fe} / \mathrm{L}$.

The final solution $\mathrm{pH}$ affects the treating performance significantly for both pharmaceuticals. When final $\mathrm{pH}$ of solution was greater than 8 , CIP removal efficiency by ferrate drops significantly. In the case of IBU, $\mathrm{pH} 4$ was the optimum $\mathrm{pH}$ for IBU removal by ferrate.

Ferrate has shown higher capability in the degradation of CIP than IBU. This is due to that CIP belongs to electron-rich organic moieties (EOM) which can be readily degraded by ferrate oxidation. Instead, the reactivity of ferrate with electronwithdrawing groups (carboxylic groups) in IBU is slow and consequently, lowers ferrate removal efficiency for the IBU.

Ferrate has shown promising performance at both $\mathrm{pH} 6$ and 8 and dose range of $1-5 \mathrm{mg} \mathrm{Fe} / \mathrm{L}$ in the treatment of real waste

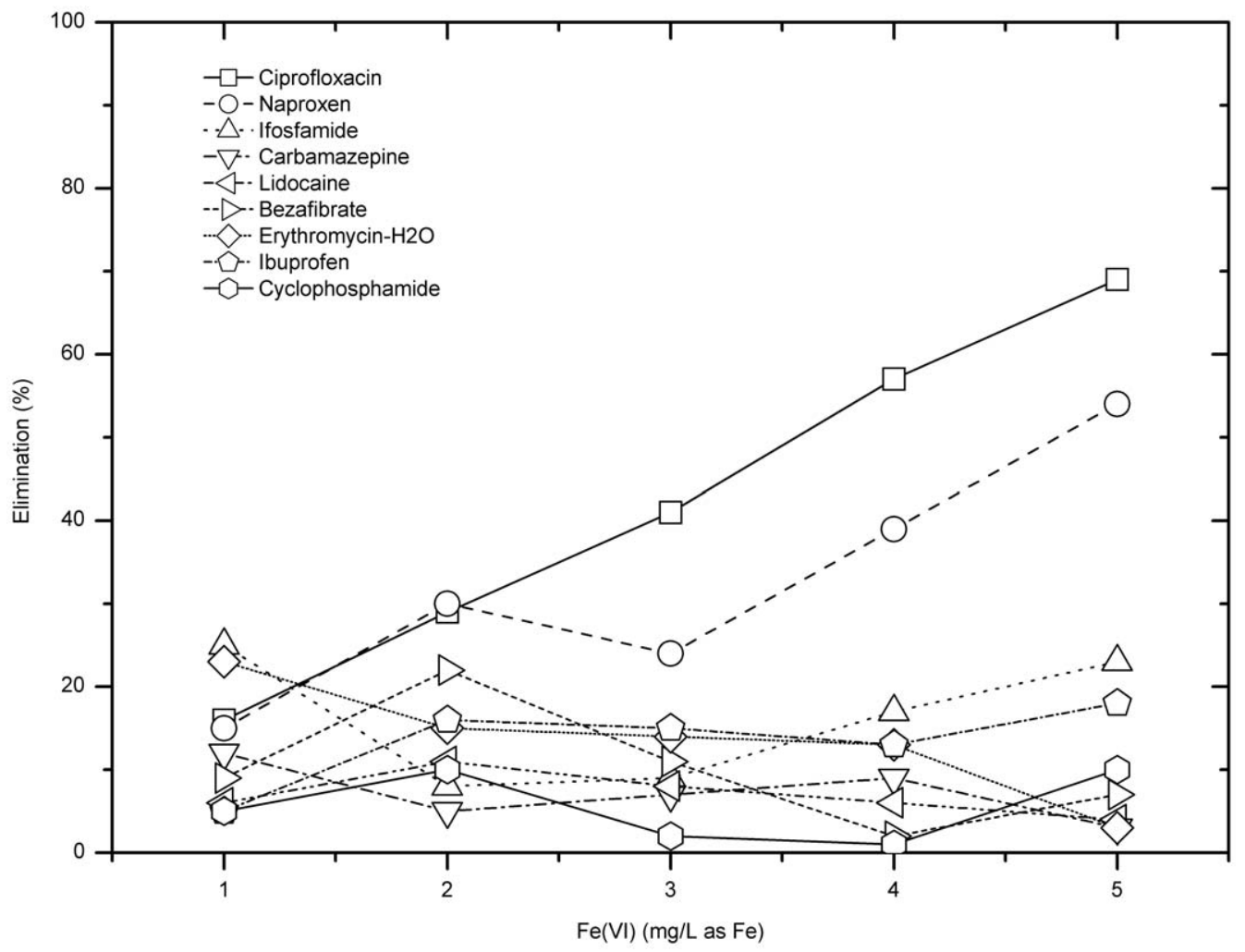

Figure 8. Pharmaceuticals removal by ferrate at pH 6.

doi:10.1371/journal.pone.0055729.g008 


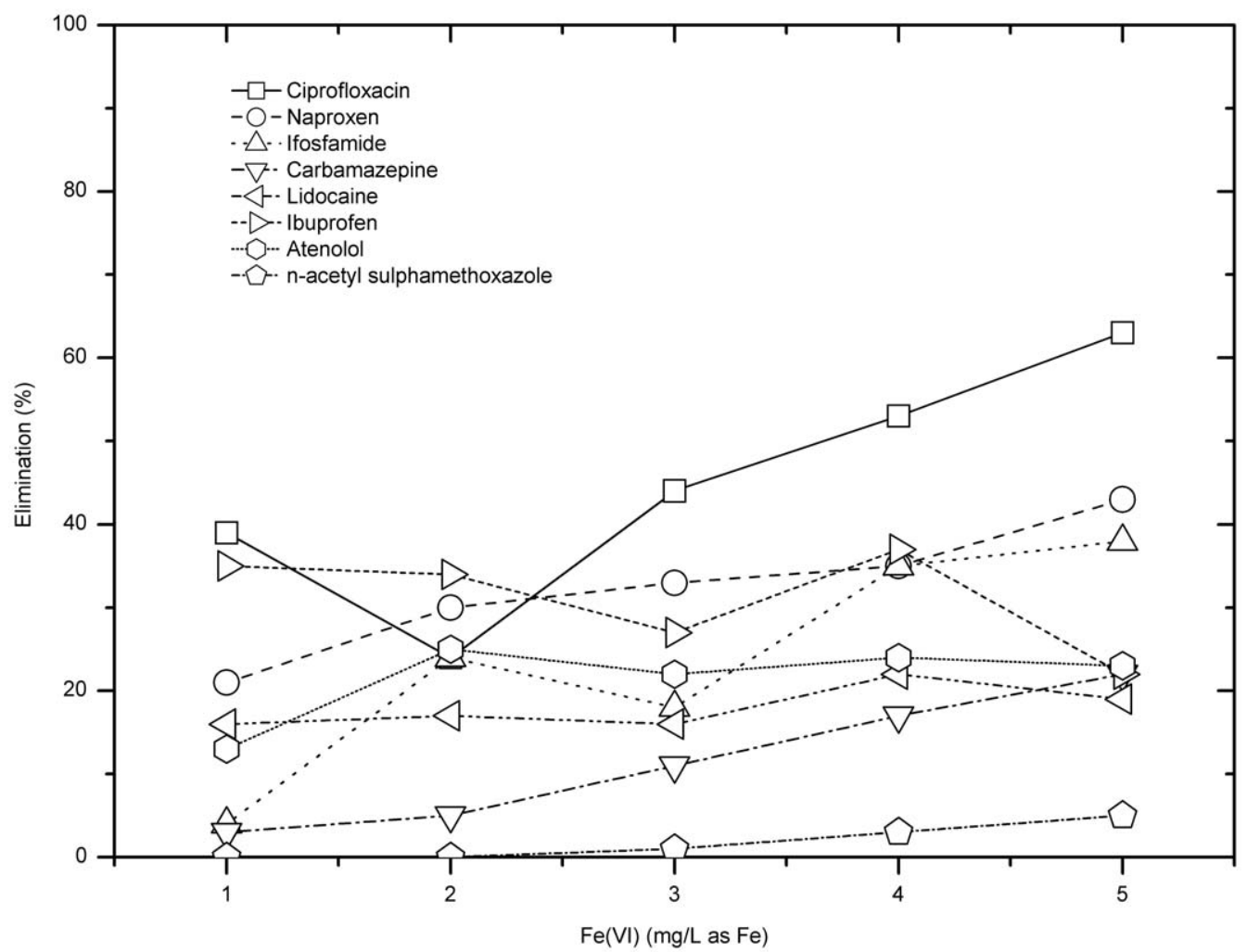

Figure 9. Pharmaceuticals removal by ferrate at $\mathbf{p H} 8$.

doi:10.1371/journal.pone.0055729.g009

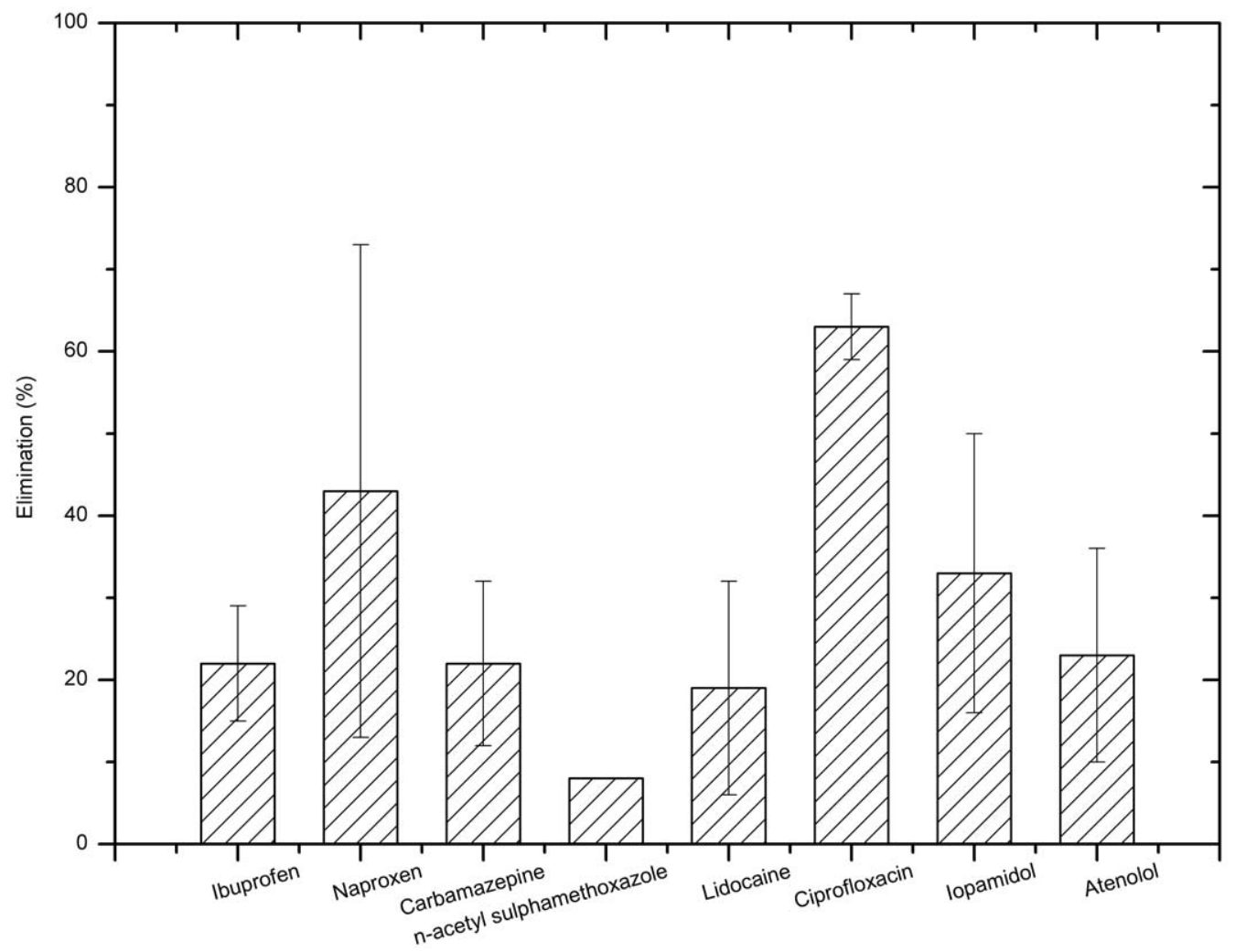

Figure 10. Pharmaceuticals removal by ferrate at $\mathrm{pH} 8$ and ferrate dose $5 \mathrm{mg} / \mathrm{L}$ as Fe. doi:10.1371/journal.pone.0055729.g010 
water effluent. Removal efficiency of ciprofloxacin was the highest among the target compounds, with an average removal of $63 \%$, followed by naproxen (43\%). On the other hand, n-acetyl sulphamethoxazole was the hardest to remove by ferrate, with an average removal of $8 \%$. Furthermore, the removal efficiencies of other compounds by ferrate were between $20 \%$ and $40 \%$.

\section{References}

1. Wang L, Ying GG, Zhao JL, Yang XB, Chen F, et al. (2010) Occurrence and risk assessment of acidic pharmaceuticals in the Yellow River, Hai River and Liao River of north China, Science of the Total Environment 408: 3139-3147.

2. Comeau F, Surette G, Brun GL, Losier R (2008) The occurrence of acidic drugs and caffeine in sewage effluents and receiving waters from three coastal watersheds in Atlantic Canada, Science of the Total Environment 396: 132-146.

3. Nakada N, Tanishima T, Shinohara H, Kiri K, Takada H (2006) Pharmaceutical chemicals and endocrine disrupters in municipal wastewater in Tokyo and their removal during activated sludge treatment, Water Research 40: 3297-3303.

4. Lishman L, Smyth SA, Sarafin K, Kleywegt S, Toito J, et al. (2006) Occurrence and reductions of pharmaceuticals and personal care products and estrogens by municipal wastewater treatment plants in Ontario, Canada, Science of the Total Environment 367: 544-558.

5. Ternes TA (1998) Occurrence of drugs in German sewage treatment plants and rivers, Water Research 32: 3245-3260.

6. Lee HB, Peart TE, Svoboda ML (2007) Determination of ofloxacin, norfloxacin, and ciprofloxacin in sewage by selective solid-phase extraction, liquid chromatography with fluorescence detection, and liquid chromatographytandem mass spectrometry, Journal of Chromatography A 1139: 45-52.

7. Ferrari B, Paxeus N, Giudice RL, Pollio A, Grric J (2003) Ecotoxicological impact of pharmaceuticals found in treated wastewaters: study of carbamazepine, clofibric acid, and diclofenac. Ecotoxicology and Environmental Safety 55 (3): 359-370.

8. Jjemba PK (2006) Excretion and ecotoxicity of pharmaceutical and personal care products in the environment. Ecotoxicology and Environmental Safety 63 (1): 113-130.

9. Grung M, Kallqvist T, Sakshaug S, Skurtveit S, Thomas KV (2008) Environmental assessment of Norwegian priority pharmaceuticals based on the EMEA guideline. Ecotoxicology and Environmental Safety 71 (2): 328-340.

10. Daughton CG, Ternes TA (1999) Pharmaceuticals and personal care products in the environment: agents of subtle change? Environmental Health Perspectives 107 (S6): 907-938.

11. Ternes TA (1998) Occurrence of drugs in German sewage treatment plants and rivers. Water Research 32 (11): 3245-3260.

12. Paxeus N (2004) Removal of selected non-steroidal anti-inflammatory drugs (NSAIDs), gemfibrozil, carbamazepine, beta-blockers, trimethoprim and triclosan in conventional wastewater treatment plants in five EU countries and their discharge to the aquatic environment. Water Science and Technology 50 (5): 253-260

13. Castiglioni S, Bagnati R, Fanelli R, Pomati F, Calamari D, et al. (2006) Removal of pharmaceuticals in sewage treatment plants in Italy. Environmental Science and Technology 40 (1): 357-363.

14. Nakada N, Tanishima T, Shinohara H, Kiri K, Takada H (2006) Pharmaceutical chemicals and endocrine disrupters in municipal wastewater in Tokyo and their removal during activated sludge treatment. Water Research 40 (17): 3297-3303.

15. Santos JL, Aparicio I, Alonso E (2007) Occurrence and risk assessment of pharmaceutically active compounds in wastewater treatment plants. A case study: Seville city (Spain). Environment International 33 (4): 596-601.

16. Okuda T, Kobayashi Y, Nagao R, Yamashita N, Tanaka H, et al. (2008) Removal efficiency of 66 pharmaceuticals during wastewater treatment process in Japan. Water Science and Technology 57 (1): 65-71.

17. Comerton AM, Andrews RC, Bagley DM, Hao CY (2008) The rejection of endocrine disrupting and pharmaceutically active compounds by NF and RO membranes as a function of compound and water matrix properties. Journal of Membrane Science 313 (1-2): 323-335.

18. Snyder SA, Adham S, Redding AM, Cannon FS, DeCarolis J, et al. (2007) Role of membranes and activated carbon in the removal of endocrine disruptors and pharmaceuticals. Desalination 202: 156-181.

19. Westerhoff P, Yoon Y, Snyder S, Wert E (2005) Fate of endocrine-disruptor, pharmaceutical, and personal care product chemicals during Simulated drinking water treatment processes. Environmental Science \& Technology 39: 6649 6663.

20. Jiang JQ (2007) Research progress in the use of ferrate(VI) for the environmental remediation, Journal of Hazardous Materials 146: 617-623.

21. Jiang JQ (2001) Development of coagulation theory and pre-polymerised coagulants for water treatment. Separation and Purification Methods 30: 127141 .

\section{Author Contributions}

Conceived and designed the experiments: JQJ ZZ. Performed the experiments: ZZ JQJ. Analyzed the data: JQJ ZZ. Contributed reagents/ materials/analysis tools: JQJ ZZ. Wrote the paper: JQJ ZZ.

22. Jiang JQ, Lloyd B, Grigore L (2001). Preparation and evaluation of potassium ferrate as an oxidant and coagulant for potable water treatment. Environmental Engineering Science 18: 323-328.

23. Jiang JQ Lloyd B (2002) Progress in the development and use of ferrate (vi) salt as an oxidant and coagulant for water and wastewater treatment. Water Research 36: 1397-1408.

24. Filip J, Yngard RA, Siskova K, Marusak Z, Ettler V (2011) Mechanisms and efficiency of the simultaneous removal of metals and cyanides by using ferrate(VI): Crucial roles of nanocrystalline iron achtungtrenung(III) oxyhydroxides and metal carbonates. Chem. Eur. J. 17: 10097-11005.

25. Sharma VK (2002) Potassium ferrate(VI): an environmentally friendly oxidant. Adv. Environ. Res. 6(2): 143-156.

26. Jiang JQ, Panagoulopoulos A, Bauer M, Pearce P (2006) The application of potassium ferrate for sewage treatment. Journal of Environmental Management 79(2): 215-220.

27. Jiang JQ, Wang S, Panagoulopoulos A (2007) The role of potassium ferrate(VI) in the inactivation of Escherichia coli and in the reduction of COD for water remediation. Desalination 210: 266-273.

28. Jiang JQ, Stanford C, Alsheyab M (2009) The online generation and application of ferrate(VI) for sewage treatment-A pilot scale trial. Separation and Purification Technology 68(2): 227-231

29. Stanford C, Jiang JQ, Alsheyab M (2010) Electrochemical production of ferrate (iron VI): application to the wastewater treatment on a laboratory scale and comparison with iron (III) coagulant. Water, Air, and Soil Pollution 209: 483488.

30. Jiang JQ, Stanford C, Mollazeinal A (2012) The application of ferrate for sewage treatment: pilot- to full-scale trials, Global NEST Journal 14 (1): 93-99.

31. Sharma VK, Sohn M, Anquandah GAK, Nesnas N (2012) Kinetics of the oxidation of sucralose and related carbohydrates by ferrate(VI). Chemosphere 87: 644-648.

32. Sharma VK (2010) Oxidation of nitrogen-containing pollutants by novel ferrate(VI) technology: A review. J. Environ. Sci. Health, A: Toxic/Hazardous Sub. Environ. Eng. 45(6): 645-667.

33. Jiang JQ, Yin Q, Zhou JL, Pearce P (2005) Occurrence and treatment trials of endocrine disrupting chemicals (EDCs) in wastewaters. Chemosphere 61(4): $544-550$.

34. Seitz W, Jiang JO, Schulz W, Weber WH, Maier D, et al. (2008) Formation of oxidation by-products of the iodinated X-ray contrast medium iomeprol during ozonation. Chemosphere 70(7): 1238-1246.

35. Yang B, Ying G-G, Zhao J-L, Liu S, Zhou L-J, et al. (2012) Removal of selected endocrine disrupting chemicals (EDCs) and pharmaceuticals and personal care products (PPCPs) during ferrate(VI) treatment of secondary wastewater effluents, Water Research 46: 2194-2204

36. Anquandah GAK, Sharma V, Knight AD, Batchu SR, Gardinali PR (2011) Oxidation of trimethoprim by ferrate(VI): kinetics, products, and antibacterial activity. Environ. Sci. Technol. 45: 10575-10581.

37. Sharma V, Luther GW, Millero FJ (2011) Mechanisms of oxidation of organosulfur compounds by ferrate(VI). Chemosphere 82: 1083-1089.

38. Sharma VK, Li XZ, Graham N, Doong RA (2008) Ferrate(VI) oxidation of endocrine disruptors and antimicrobials in water. Water Supply: Res. Technol. AOUA 57(6): 419-426.

39. Lee Y, Zimmermann SG, Kieu AT, von Gunten U (2009) Ferrate (Fe(VI) Application for Municipal Wastewater Treatment: A Novel Process for Simultaneous Micropollutant Oxidation and Phosphate Removal, Environ. Sci. Technol. 43: 3831-3838.

40. Carr JD, Kelter PB, Tabatabai A, Splichal D, Erickson J, et al. (1985) Properties of ferrate (VI) in aqueous solution: an alternate oxidant in wastewater treatment, In Jolley, R. L. Et Al., 1285-1298.

41. Zhou Z, Jiang JQ (2012) Detection of ibuprofen and ciprofloxacin by solid phase extraction and UV/Vis spectroscopy, J. Applied Spectroscopy 79 (3): 477-481.

42. Jiang JQ, Zhou Z, Pahl O (2012) Preliminary study of ciprofloxacin (cip) removal by potassium ferrate(VI). Separation and Purification Technology 88: 95-98.

43. Sharma,VK, Mishra SK (2006) Ferrate(VI) oxidation of ibuprofen: A kinetic study. Environmental Chemistry Letters 3: 182-185.

44. Hu L, Martin HM, Arce-Bulted O, Sugihara MN, Keating KA, et al. (2009) Oxidation of carbamazepine by $\mathrm{Mn}(\mathrm{VII})$ and $\mathrm{Fe}(\mathrm{VI})$ : reaction kinetics and mechanism. Environ. Sci. Technol. 43: 509-515.

45. Sharma VK, Burnett CR, Millero FJ (2001) Dissociation constants of the monoprotic ferrate(VI) ion in NaCl media. Phys. Chem. Chem. Phys. 3: 2059 2062. 